\title{
CONFLITOS ENTRE PAIS E FILHOS BATEM À PORTA DO CONSELHO TUTELAR
}

CONFLICTOS ENTRE PADRES E HIJOS LLAMAN

A LA PUERTA DEL CONSEJO TUTELAR

\section{CONFLICTS BETWEEN PARENTS AND CHILDREN KNOCK ON THE DOOR OF THE CHILD PROTECTIVE COUNCIL}

ÉRICA DOS SANTOS VIEIRA ${ }^{12}$

\section{LEILA MARIA TORRACA DE BRITO ${ }^{3}$}

${ }^{1}$ Prefeitura Municipal de Niterói, RJ, Brasil

2 Universidade Estácio de Sá, Niterói/RJ, Brasil

${ }^{3}$ Universidade do Estado do Rio de Janeiro, Brasil

Recebido em: 25/10/2019 Aprovado em: 07/03/2020
RESUMO: Neste artigo busca-se refletir sobre questões contemporâneas que podem estar contribuindo para certo sentimento de perda de autoridade parental, relatado por um número considerável de pais e mães que procura o Conselho Tutelar indagando-se, também, sobre o papel do referido órgão perante tais situações. A partir da compreensão da autoridade parental como relacionada ao lugar genealógico ocupado pelos responsáveis no que tange à transmissão geracional, foi possível circunscrever, com 0 apoio da bibliografia utilizada, alguns fatores contemporâneos que poderiam colaborar para 0 quadro aqui apresentado. Destacam-se, no trabalho, o (des)entendimento sobre as leis de proteção à infância, a medicalização da vida, o estreitamento das fronteiras geracionais e os meios de comunicação de massa. Conclui-se que o Conselho Tutelar deve fornecer apoio para que os responsáveis possam efetuar a transmissão geracional, o que certamente não significa ocupar o lugar deles.

Palavras-chave: Conselho Tutelar; Relações familiares; Direitos da criança.

RESUMEN: Este artículo pretende reflexionar sobre temas de actualidad que pueden contribuir a cierta sensación de pérdida de la autoridad de los padres, por un numero considerable de madres y padres que buscan el Consejo Tutelar, cuestionando también acercade el papel de ese órgano vis-á-vis tales situaciones. Basado en la comprensión de la autoridad de los padres en relación con el lugar genealógico ocupado por responsables con respecto a la transmisión generacional, fue posible poner de relieve, con el apoyo de la bibliografía, algunos factores contemporáneos que podrían colaborar con el cuadro presentado aquí. Se destacan en el trabajo, la (mal)entendido en las leyes de protección del niño, la medicalización de la vida, el estrechamiento de las fronteras generacionales y los medios de comunicación. Se concluye que el Consejo Tutelar debería proporcionar apoyo para que los responsables puedan hacer la transmisión generacional, que sin duda no significa el Consejo ocupar el lugar de ellos.

Palabras clave: Consejo Tutelar; Relaciones familiares; Derechos del niño.

ABSTRACT: This article seeks to reflect on contemporary issues that may be contributing to a certain feeling of loss of parental authority, reported by a considerable number of mothers and fathers who seek the Child Protective Council inquiring, also, about the role of that organ vis-à-vis such situations. Understanding parental authority as related to the genealogical place occupied by parents with respect to generational transmission, it was possible to be limited, with the support of the bibliography used, some contemporary factors that could collaborate to the framework presented here. Stand out in work, the (mis) understanding on child protection laws, the medicalization of life, the narrowing of the generational borders and the mass media. It is concluded that Child Protective Council should provide support so that those parents can make the generational transmission, which certainly does not mean take the place them

Keywords: Tutelary Council; Family relationships; Rights of the child. 


\section{INTRODUÇÃO}

De acordo com o Estatuto da Criança e do Adolescente (ECA), cada município brasileiro deve ter, no mínimo, um Conselho Tutelar definido como um órgão não jurisdicional e autônomo, que tem o papel de zelar pelos direitos infanto-juvenis. Para seu funcionamento são escolhidos pela população local cinco conselheiros, remunerados pelo município, que podem contar com recursos humanos e administrativos por parte do poder executivo municipal. Embora o Conselho Tutelar esteja vinculado administrativamente ao município, ele é autônomo no que diz respeito às suas decisões, de acordo com o disposto no Art. 131 do ECA.

Além dos conselheiros, muitos Conselhos Tutelares contam com o suporte administrativo de profissionais de ensino médio, bem como atuação de profissionais de nível superior que compõem a equipe técnica. Todavia, apesar de o trabalho neste órgão ser desempenhado de forma articulada, as decisões institucionais são tomadas pelo colegiado formado pelos cinco conselheiros.

A definição sobre os possíveis recursos materiais e humanos, necessários para a execução das atividades dos Conselhos Tutelares, dependerá de critérios traçados por cada município, conforme explicitado no Art. 134 do ECA. Por esse motivo, é possível encontrar um quadro diverso ao longo do território nacional. Enquanto em alguns municípios os Conselhos Tutelares contam com uma equipe técnica própria, em outros não se vislumbra essa possibilidade (Digiácomo, 2016). Sabe-se, no entanto, que, quando estão presentes, os profissionais que compõem a equipe geralmente têm formação nas seguintes áreas: serviço social, psicologia, direito e pedagogia. Embora seja salientada a relevância do trabalho da equipe técnica, este não deve ser confundido com as atribuições dos conselheiros e, tampouco, com aquelas desempenhadas pela rede de proteção à criança e ao adolescente (arts. 86, 87 e 88 do ECA). Sua função é a de auxiliar os conselheiros no acolhimento, compreensão e encaminhamento dos casos, utilizando para tanto os conhecimentos específicos de cada área. Esta parceria, na prática, é bastante enriquecedora, uma vez que possibilita a articulação de diferentes saberes, ampliando o olhar acerca de questões que são encaminhadas por famílias que buscam ajuda do órgão.

Por meio de trabalho na equipe técnica de um Conselho Tutelar, localizado em município na região metropolitana de um estado da região sudeste do país, foi possível observar quantidade expressiva de casos relacionados a conflitos vivenciados no âmbito familiar, mais especificamente nas relações entre pais, mães e filhos. Desavenças, atritos, discordâncias, incompatibilidades pequenas, ou grandes hostilidades entre os responsáveis e seus filhos adolescentes transformavam-se em demandas dirigidas ao órgão, em uma tentativa de "pedir ajuda para repreender os filhos", como também observou Asth (2010, p. 74). Evidenciava-se a dificuldade encontrada por pais e mães em lidar, de forma autônoma, com questões relacionadas à educação desses filhos. Muitos se queixavam da perda de autoridade sobre os adolescentes, que já não obedeciam às suas solicitações, ou mesmo determinações.

As situações que ocasionavam a busca por apoio eram diversas, tais como: o adolescente não respeitava o horário de retorno para casa; desejava ir a festas e eventos considerados inapropriados; fugia de casa na calada da noite; permanecia fora da residência por dias seguidos; fazia uso de drogas lícitas ou ilícitas. No que diz respeito ao colégio, o jovem geralmente apresentava baixa frequência escolar; passava muitas horas na internet ou dormindo - investindo pouco tempo nos estudos; dormia muito tarde; apresentava comportamento desrespeitoso com educadores e demais profissionais. Constava também das queixas o fato de o adolescente gastar dinheiro ou utilizar cartões de crédito sem autorização; as relações amorosas ou

Nova Perspectiva Sistêmica, v. 29, n. 66, p. 74-86, abril 2020. 
de amizade com pessoas que os responsáveis desaprovavam; a recusa a ajudar nas atividades domésticas ou a supervisionar os irmãos mais novos, além de agressões verbais ou físicas aos próprios pais, mães e a outras pessoas.

Os responsáveis pareciam desorientados, tateando no escuro, enquanto buscavam algum caminho factível que lhes permitisse retomar o controle da situação. Em sua campanha pelo restabelecimento do que consideravam hierarquia familiar, alguns ameaçavam recorrer aos castigos físicos como estratégia disciplinar. Segundo explicitavam, este recurso seria empregado quando esgotassem todas as possibilidades de entendimento por meio de conversas. Todavia, a experiência no atendimento a essas famílias demonstrava que tal alternativa, certamente, não seria eficaz quanto à resolução do problema gerando, por sua vez, ameaças dos filhos de que denunciariam seus pais e mães ao Conselho Tutelar por agressão.

Por outro lado, tão comum quanto as reclamações formuladas pelos adultos eram os desabafos dos adolescentes, que alegavam sofrer cobranças exacerbadas e se sentiam cerceados em sua liberdade. Asseguravam que eram maduros o suficiente para tomar suas próprias decisões sem a interferência dos responsáveis e incomodavam-se com as sucessivas tentativas do que nomeavam de "controle do seu comportamento". Consequentemente, a relação parento-filial era percebida por um viés adversarial, com pais e filhos ocupando posições antagônicas.

Nesse contexto, era possível perceber que as chamadas práticas de judicialização e medicalização da existência (Oliveira \& Brito, 2013) eram estratégias frequentemente adotadas pelos responsáveis na tentativa de retomar o controle da situação que, por vezes, entendiam ter sido fomentada pelos meios de comunicação ou pelas leis de proteção à infância. Assim, buscavam principalmente o apoio do Conselho Tutelar e de consultórios de profissionais de saúde mental na procura por ferramentas que pudessem auxiliá-los a exercer alguma autoridade sobre os filhos. Cabe ressaltar que, embora o Conselho Tutelar não seja considerado órgão da justiça, o nexo de seu trabalho é dado fundamentalmente pelo Estatuto da Criança e do Adolescente (ECA), o que levava algumas pessoas a considerarem que o Conselho seria subordinado ao Juizado da Infância e da Juventude.

Frente às dificuldades expostas à equipe técnica surgiam inúmeros questionamentos que incluíam possibilidades, ou não, de atuação do Conselho Tutelar junto às famílias atendidas. O que motivaria esse sentimento de perda de autoridade sobre os filhos explicitado pelos responsáveis? O contexto contemporâneo estaria contribuindo de alguma forma? Pais e mães estariam perdendo sua autoridade em virtude de leis que buscam garantir os direitos infanto-juvenis, ou devido a certos programas veiculados pela mídia, como por vezes explicitavam? Haveria relação entre essas questões e o processo de medicalização da infância?

Neste sentido, a partir da compreensão da autoridade parental como relacionada ao lugar genealógico ocupado pelos responsáveis no que tange à transmissão geracional (Hurstel, 2006; Legendre, 1999), no artigo em tela busca-se refletir sobre algumas questões contemporâneas que podem estar colaborando com o sentimento de perda da autoridade parental relatado por muitos responsáveis atendidos no Conselho Tutelar, bem como indagar sobre atribuições do referido Conselho perante tais situações. O caminho que se optou foi o de circunscrever e examinar fatores e situações constantemente apontados pelos pais e mães como sendo os que, de alguma forma, podem ensejar o quadro que ora se anuncia.

Compreende-se que muitos problemas vivenciados no âmbito privado, como aqueles levados ao Conselho Tutelar, não podem ser reduzidos à esfera individual, por estarem visceralmente relacionados ao contexto macropolítico. 
Como também notaram Nascimento e Scheinvar (2010, p. 27), "no Conselho, temos localizado a existência de uma lógica de atuação pautada na tentativa de apaziguar os conflitos e trazer soluções definitivas”. Procurou-se, portanto, fugir de concepções que tratam o assunto como se dissesse respeito apenas a fatores próprios desses sujeitos.

\section{A AUTORIDADE NO CONTEXTO CONTEMPORÂNEO: UM DESAFIO AO EXERCÍCIO DOS PAPÉIS PARENTAIS}

Antes de discorrer sobre a questão da autoridade parental, parece importante examinar melhor o conceito de autoridade em si. Que é autoridade? Este é o título de um relevante capítulo da obra "Entre o passado e o futuro" (1954/2016), publicado pela filósofa alemã Hannah Arendt, no qual apresenta a origem filosófica e política do termo.

Ao abordar a questão específica, Arendt prefere partir da explicação sobre o que não deve ser considerado autoridade para tentar circunscrever o que, de fato, estaria no âmago da análise. A autora explicita os equívocos comuns ao se empregar o termo de forma indiscriminada.

Visto que a autoridade sempre exige obediência, ela é comumente confundida com alguma forma de poder ou violência. Contudo, autoridade exclui a utilização de meios externos de coerção; onde a força é usada, a autoridade em si mesmo fracassou. A autoridade, por outro lado, é incompatível com a persuasão, a qual pressupõe igualdade e opera mediante um processo de argumentação. Onde se utilizam argumentos a autoridade é colocada em suspenso. Contra a ordem igualitária da persuasão ergue-se a ordem autoritária, que é sempre hierárquica. Se a autoridade deve ser definida de alguma forma, deve sê-lo, então, tanto em contraposição à coerção pela força como à persuasão por meio dos argumentos (Arendt, 1954/2016, p.129).

Na publicação coordenada por Bruel (1998), há destaque para a compreensão de Hannah Arendt de que a autoridade não significa autoritarismo, mas "ela procede do reconhecimento de alguém como fundado a se exprimir a partir de um certo lugar" (p.103), ou seja, no caso da autoridade parental, é o Estado, por meio de suas leis, que irá determinar poderes e deveres dos pais. Portanto, pais e mães não são apenas genitores, mas aqueles que possuem responsabilidade perante a socialização dos filhos.

$\mathrm{Na}$ atualidade, como expõe Hurstel (2006), aponta-se uma lacuna aberta no lugar onde deveria haver autoridade de pais e mães, indicando dificuldades encontradas por esses em ocupar o chamado lugar genealógico que lhes foi reservado. Esse lugar não é dado biologicamente, mas é ocupado na medida em que o sentido de filiação é passado para o filho, de modo que cada elo dessa cadeia geracional, após receber o que foi transmitido por seu ascendente, sente-se compelido a fazer o mesmo por seus descendentes, sendo apenas possível fazê-lo porque um dia o recebeu. Por outro lado, há o entendimento de que a origem da questão se encontra atrelada a fatores que extrapolam a mera limitação individual de pais e mães. É possível pensar que determinados componentes da vida moderna estariam interferindo na relação parento-filial de forma contundente, contribuindo para esse desfecho. "Eles se sentem responsáveis, e não podem ser considerados culpados. 
Estão envolvidos num vasto movimento de mutação da autoridade, que os ultrapassa, e vai além da área educativa" (Hurstel, 2006, p.166).

Théry (1998), por sua vez, não compartilha a visão daqueles que propõem a troca do termo autoridade por responsabilidade parental. A autora defende que o primeiro termo é mais amplo, abrangente, já englobando a responsabilidade. Explica ainda Théry (1998) que "a palavra autoridade vem do latim auctoritas, e indica simbolicamente tudo que representa o fato de se reconhecer autor da criança" (p.190). Argumenta, também, que o Estado deve proteger a autoridade parental, pois é ele quem delega a pais e mães o exercício dessa função, que não é exclusivamente privada, nem pode ser confundida com autoritarismo. Dekeuwer-Défossez (1999, p.13) reconhece, entretanto, que não se pode exagerar o papel do Direito no que diz respeito aos relacionamentos familiares, como também não se deve negligenciá-lo, pois este possui considerável valor simbólico. Assim, compreende que, ao se sustentar a autoridade parental, se está assegurando, para as crianças, sua filiação. Portanto, para esta autora: "os direitos da criança não devem ser colocados de maneira exclusivamente antagônica aos de seus pais e aos dos adultos" (p.17).

Com base nestas reflexões, um questionamento se faz pertinente neste momento. Se a autoridade parental se traduz na capacidade de ocupar o lugar genealógico, conforme aponta Hurstel (2006), o que poderia estar oferecendo obstáculos para que pais consigam obter êxito neste sentido?

\section{RESSONÂNCIAS DAS LEIS DE PROTEÇÃO SOBRE A RELAÇÃO PARENTO-FILIAL}

Ouve-se de muitos pais e mães atendidos no Conselho Tutelar frases do tipo: "O ECA é uma eca!"; "Se eu não cuidar bem do meu filho, o Conselho Tutelar vem atrás de mim"; "Os adolescentes de hoje têm muitos direitos, mas nenhum dever!"; "Para o Conselho Tutelar os pais sempre estão errados"!; "Eu trouxe meu filho aqui pra vocês darem uma solução, já que eu não posso fazer nada com ele!"; "Eu quero entregar meu filho para o Conselho Tutelar porque ele não me obedece!”.

Faltaria espaço neste artigo para reproduzir a infinidade de sentenças proferidas pelos responsáveis, as quais evidenciam o quanto se sentem desautorizados frente aos filhos. E mais, indicam que se percebem ameaçados pelas leis de proteção à infância e à adolescência, temendo sofrer alguma punição no exercício de sua autoridade parental. Além de certo desconhecimento sobre o teor da lei e sobre as atribuições do Conselho Tutelar, o temor desses responsáveis parece ter relação com o tipo de funcionamento social característico da contemporaneidade, quando se multiplicam as práticas punitivas e o denuncismo, como bem observou Souza (2014).

Testemunha-se, no presente, o clamor pela aprovação de inúmeros projetos de leis que se aliam à expansão vertiginosa do poder judiciário sobre os diferentes campos da vida pública e privada, regulando modos de existência dos indivíduos. Esse fenômeno tem sido denominado por alguns autores, como Oliveira e Brito (2013), de judicialização.

Compreendemos como judicialização o movimento de regulação normativa legal do viver, do qual os sujeitos se apropriam para a resolução dos conflitos cotidianos. Atravessados pelo Poder Judiciário, não somente se recorre a ele como também se incorporam e se legitimam seus modos de operação, reproduzindo-se o controle, o julgamento e a punição das condutas, em prol - assim é justificado - da inviolabilidade dos direitos, do melhor interesse, da proteção e do bem-estar de algumas vidas. (Oliveira \& Brito, 2013, p. 80)

Nova Perspectiva Sistêmica, v. 29, n. 66, p. 74-86, abril 2020. 
Os conflitos parento-filiais que chegam ao Conselho Tutelar ilustram bem esse movimento de judicialização da vida. Neste sentido, este órgão recebe diariamente pais e mães que buscam amparo para que possam sustentar sua tomada de decisão frente aos filhos. Foi assim no caso de mães que procuraram atendimento no órgão após serem ameaçadas, por filhos adolescentes, de serem denunciadas por cárcere privado. Justificavam que a motivação dos adolescentes teria sido o fato de terem ficado de castigo, sem celular ou sem ver os amigos devido ao comportamento desrespeitoso que apresentavam. Algo semelhante ocorreu com pais, que chegavam ao Conselho Tutelar relatando que os filhos haviam ido para a casa de amigos e se recusavam a retornar. Os responsáveis ficavam em dúvida se poderiam obrigá-los a regressar ao convívio familiar, sem, com isso, sofrerem punições. Exemplos como esses se sucedem no dia a dia dos atendimentos no Conselho.

Ao que parece, no entendimento desses pais e mães é como se coubesse ao Conselho - em virtude de ser um órgão encarregado de zelar pelos direitos infantojuvenis - classificar ações dos responsáveis, legitimando-as ou condenando-as de acordo com a lei. Os conselheiros tutelares, estes sim, teriam capacidade de decidir sobre como deve ser conduzida a educação dos adolescentes.

Nesses exemplos, torna-se perceptível que o movimento de judicialização da vida produziu, e ainda produz, ressonâncias sobre as relações parento-filiais. Em tais circunstâncias, o exercício da autoridade parental se vê submetido ao crivo do poder público, que se impõe de forma insidiosa sobre a vida familiar. Ao mesmo tempo, observa-se a difusão da cultura do medo e da vigilância, que se materializa sob a forma de denúncias. Pais e mães percebem suas ações sendo alvo do escrutínio público, os vizinhos tornam-se denunciantes em potencial e até os próprios filhos, em alguns casos, proferem ameaças.

\section{INFORMAÇÃO E FORMAÇÃO PELOS MEIOS DE COMUNICAÇÃO DE MASSA}

Nota-se que, com o avanço tecnológico, foi incorporada ao cotidiano familiar uma série de instrumentos de difusão da informação, sendo os mais populares: a televisão e a internet. $\mathrm{Na}$ atualidade, muitos lares brasileiros possuem um aparelho de TV e/ou conexão com a internet. De acordo com dados do Instituto Brasileiro de Geografia e Estatística (IBGE, 2016), no ano de 2015 o país contabilizava 68,0 milhões de domicílios, dos quais 66,1 milhões $(97,1 \%)$ possuíam aparelho de televisão. Quanto ao acesso à internet, em 2015, o percentual alcançado foi 57,8\%, equivalente a 39,3 milhões de domicílios.

A transmissão da informação ocorre em velocidade nunca antes vista. Alguns autores, como Costa (2006), analisam os efeitos dessa realidade sobre as famílias, principalmente no que tange a profusão de discursos e modos de ser hegemônicos. Para ele, os veículos de comunicação em massa desempenham um papel decisivo na produção de sentidos para a experiência cotidiana dos indivíduos. Desta forma, diferentes elementos presentes na cultura midiática estariam sendo incorporados à vida familiar, colaborando para a mudança de valores que, até então, formavam sua base. São valores e modelos de conduta difundidos pelos meios de comunicação, que mesclam projeção e assimilação, assim como informação e formação. Como analisa Sarlo (1994), “a televisão constrói seu público para poder refleti-lo, e o reflete para poder construí-lo" (p. 89).

As mensagens transmitidas pela mídia nem sempre estão de acordo com o que a família e a escola consideram apropriado no que se refere ao conteúdo a ser transmitido às crianças e aos adolescentes. Portanto, causa preocupação o fato 
de que, no contexto atual, muitas crianças e adolescentes passem um período excessivo de tempo fazendo uso dessa tecnologia. No que diz respeito à televisão, Dufour (2003/2005) chama atenção para o fato de crianças da mais tenra idade permanecerem várias horas por dia diante do aparelho, mesmo antes de começarem a falar. Trata-se de um meio encontrado pelos pais para deixar os filhos ocupados, enquanto se dedicam a outras atividades da vida doméstica ou laboral.

Nas palavras do autor:

A inundação do espaço familiar por essa torneira sempre aberta de onde corre um fluxo ininterrupto de imagens não deixa de ter, evidentemente, efeitos consideráveis na formação do futuro sujeito falante. Em primeiríssimo lugar, a televisão, pelo lugar preponderante ocupado por uma publicidade onipresente e agressiva, constitui um verdadeiro adestramento precoce para o consumo e uma exortação à monocultura da mercadoria. Aliás, essa incitação excessiva não é desprovida de visadas ideológicas (Dufour, 2003/ 2005, p. 121).

O menor período de convivência entre pais e filhos, motivado pelos fatores descritos, faz com que a televisão furte aos primeiros o papel na educação das crianças, bem como reduz o intervalo de tempo destinado a outras aprendizagens. $\mathrm{Na} \mathrm{TV}$, as crianças aprendem sobre os mais diferentes conteúdos antes mesmo que tenham desenvolvido maturidade para isso. São ensinadas desde cedo sobre quais produtos devem consumir, quais os padrões sociais que devem seguir para se tornarem pessoas de sucesso, como devem lidar com os adultos e quais os valores que devem cultivar. Neste sentido, o papel familiar da transmissão geracional pode se tornar prejudicado, como bem reflete Dufour (2003/2005).

Nota-se que, como os bens de consumo, constantemente novas temáticas e problemas são apresentados aos sujeitos a partir de matérias divulgadas pela mídia que, com frequência, enaltece a pertinência de encaminhamentos ao judiciário ou, ainda, apresenta a questão como uma nova doença ou transtorno psicológico. Para melhor conhecimento do assunto rapidamente são elaboradas cartilhas, com orientações pragmáticas, visando à divulgação do tema por aqueles que prontamente se apresentam como especialistas.

Com a invasão do espaço familiar por certo saber especializado divulgado pela mídia, os responsáveis perderam espaço no que tange ao protagonismo na educação das futuras gerações. Mais do que isso, podem ser alvo de críticas efusivas no que diz respeito ao modo como tratam suas crianças, sendo acusados de autoritarismo. O combate às ações autoritárias atinge em cheio a autoridade parental, quando não se faz uma distinção clara entre os excessos praticados por alguns responsáveis e o princípio de autoridade parental. Como destacam Zanetti \& Gomes (2009),

nossa leitura deste movimento no universo intelectual sobre a infância nos faz pensar que em busca de relações mais igualitárias entre os sexos e isenta de repressões sexuais, diversos autores e profissionais especializados, procurando propiciar melhores condições de vida aos novos seres humanos, acabaram se confundindo entre um combate ao autoritarismo e o princípio de autoridade, que passaram a ser concebidos sem distinção nos lares, de modo que ambos passaram a ser atacados e questionados (p.197). 
A medicalização da existência é um fenômeno que tem se destacado em discussões travadas na atualidade (Decotelli, Bohre, \& Bicalho, 2013), tendo em vista a proporção e a rapidez com que vem se intensificando nos últimos anos. Encontra-se em estreita articulação com o desenvolvimento do conhecimento científico e a criação de tecnologias de intervenção sobre o corpo humano, os quais não apenas ampliaram as possibilidades de cuidado em saúde, como também contribuíram para que alguns comportamentos humanos fossem reduzidos a sintomas patológicos.

Definimos medicalização da vida como um processo bastante imbricado com a sociedade do nosso tempo, na qual o saber médico se estende às mais diversas áreas implicadas com o bem-estar humano. Problemas cotidianos do existir, como sexualidade, infelicidade, degradação biológica, envelhecimento, solidão, e morte, passando pelas várias etapas da vida, desde os recémnascidos, às crianças e mulheres grávidas até as que estão no climatério e os que chegam à velhice, são tratados sobre a égide da Medicina e de seus cuidados em termos de problemas médicos, ou seja, de doenças, síndromes ou condições. (Decotelli et al., 2013, p. 451).

Segundo alguns autores (Bezerra, 2010; Brito \& Rocha, 2016), os parâmetros atuais para o estabelecimento de diagnósticos psiquiátricos são questionáveis, pois abarcam um grupo considerável de comportamentos até então considerados normais. Em decorrência disso, observa-se um aumento expressivo no número de sujeitos identificados como portadores de transtornos mentais. Na formulação de tais diagnósticos, são utilizados certos argumentos de cunho científico que contribuem para enquadrar como doentes aqueles cujos comportamentos destoam da maioria. A vida assim, dividida entre normalidade e anormalidade, perde o caráter de multiplicidade que lhe é intrínseco (Brzozowski \& Caponi, 2013).

Em se tratando de crianças e adolescentes, percebe-se uma tendência de aumento de indicação de uso de drogas psicotrópicas em idades cada vez mais tenras. Esse fato vem sendo anunciado em diversas publicações, nas quais se nota evidente preocupação com as possíveis repercussões que práticas de medicalização da vida possam ter sobre a subjetividade da população infanto-juvenil (Brzozowiski \& Caponi, 2013; Decotelli et al., 2013; Dufour, 2003/2005).

Frente à proporção do problema, em 2010, no Brasil, foi criado o "Fórum sobre Medicalização da Educação e da Sociedade", integrado por diversas organizações da sociedade civil, tendo como objetivo articular ações dos diferentes atores, com vistas ao seu enfrentamento. De acordo com os dados de uma publicação do Conselho Federal de Psicologia (CFP, 2012), o país é o segundo no ranking mundial do uso de metilfenidato, droga comumente utilizada no tratamento de crianças diagnosticadas com Transtorno de Déficit de Atenção com Hiperatividade (TDAH). Ainda segundo informações daquele Conselho de classe, o consumo dessa substância teria saltado de 71.000 caixas no ano 2000, para 2.000.000 de caixas no ano de 2010 .

Esta realidade torna-se notória nos atendimentos realizados no Conselho Tutelar, uma vez que boa parte dos adolescentes atendidos faz, ou já fez, acompanhamento psiquiátrico, com ou sem uso de medicação controlada. Chama atenção, nestes casos, o fato de os motivos que conduziram ao consultório do psiquiatra serem bastante

Nova Perspectiva Sistêmica, v. 29, n. 66, p. 74-86, abril 2020. 
similares àqueles que provocaram a busca pela ajuda do Conselho Tutelar. De forma sucinta, dizem respeito ao comportamento do adolescente, que apresenta atitudes e emoções consideradas inadequadas pela família e pelas pessoas com quem convive, sendo classificados ora como rebeldes, ora como doentes.

Cabe mencionar, ainda, que a patologização da existência transfere para o campo médico as explicações acerca dos conflitos e mal-estares vivenciados no cotidiano dos adolescentes. Via de regra, reduz questões complexas, de ordem coletiva, à esfera individual, inviabilizando com isso a construção de uma leitura crítica sobre a realidade, bem como a produção de interrogações acerca das circunstâncias reais imbricadas nesse processo.

O discurso medicalizante, esvazia também a responsabilidade dos diversos atores sociais (escola, família, comunidade etc.) como importantes interlocutores na construção desse discurso próprio pelo adolescente. ... nas sociedades ocidentais, é crescente a translocação para o campo médico de conflitos inerentes à vida, com a transformação de questões coletivas, de ordem social e política, em questões individuais, biológicas. (Moreira \& Coutinho, 2018, p.61)

Para os responsáveis, parece um alívio ouvir do médico que o filho possui um transtorno de ordem biológica que o impede de se submeter à sua autoridade. Espera-se, assim, que o jovem seja medicado para que a ordem familiar seja restabelecida. Quanto à escola, soa como mais simples tentar enquadrar o aluno por meio de categorias nosológicas do que produzir alguma interpelação acerca do modelo de ensino ou das condições em que se encontram os colégios, como já destacaram Brito e Rocha (2016).

\section{PAIS OU AMIGOS? A QUESTÃO DA AUTORIDADE PARENTAL E DAS FRONTEIRAS GERACIONAIS}

Zanetti e Gomes (2011) compreendem que se observa na atualidade uma 'fragilização das funções parentais'. Utilizam tal denominação para se referirem aos sentimentos de insegurança, dúvida e medo experimentados por alguns pais e mães diante das injunções da vida moderna, quando se sentem inaptos a exercer papel de responsáveis pela educação dos seus filhos. Nos dias de hoje, se uma criança chora constantemente, se é introvertida demais, se tem algum machucado visível, se não parece adequadamente asseada, se passa tempo demais na rua ou tempo demais em casa, se come muito doce ou pouco come, qualquer um destes itens é passível de gerar denúncia ao Conselho Tutelar. Por vezes, situações corriqueiras que permeiam a convivência familiar são enquadradas por meio de especificações genéricas como: negligência, maus-tratos, violência psicológica e outras.

No debate sobre a importância de valorização da autoridade parental destaca-se, mais uma vez, o relatório emitido por Bruel (1998) que, em um dos itens do trabalho, traz a discussão de como "Assegurar as bases da autoridade parental", uma questão política, para a qual o Estado não pode deixar de prestar atenção no contexto atual. Naquele relatório se encontra a advertência de que se não há intenção de colocar um policial, ou um trabalhador social, atrás de cada jovem, é preciso "revitalizar a função familiar de transmissão de valores" (Bruel, 1998, p.59).

Para Legendre (1999), este é um ponto central, mas de difícil encaminhamento, "pois é aí que o princípio da vida está ancorado: como os pais se colocam frente 
aos filhos? Como os filhos se colocam frente aos pais?" (p.86). O autor se preocupa com a maneira como essa questão tem sido encaminhada pela sociedade, afirmando que são as montagens institucionais, nas quais estão incluídas leis e jurisprudências, "que ordenam e ultrapassam a relação dual (entre pais e filhos) introduzindo um terceiro termo" (p.87), sendo o Estado responsável pelo que denomina de "justiça genealógica” (p.87).

Não se poderia deixar de mencionar que mudanças no funcionamento familiar contribuíram para que, na contemporaneidade, as figuras parentais, que por vezes se impunham por meio do distanciamento afetivo em relação aos filhos, sejam por vezes mais acessíveis. Essa aproximação pode favorecer a construção de uma comunicação mais franca entre os responsáveis e seus filhos, que agora podem falar sobre assuntos antes impensáveis - como sexo e drogas. Por outro lado, de acordo com Stengel (2011), nota-se também certa diluição das fronteiras que demarcavam a diferença entre uma e outra geração permitindo, por vezes, que pais e mães ocupem apenas o lugar de amigos de seus filhos abandonando, em alguns casos, seu lugar na transmissão geracional. "As diferenças geracionais têm tido suas fronteiras cada vez mais difusas, em que se observa, com frequência, uma tentativa de pais estarem mais próximos de seus filhos, fazerem as mesmas atividades, usarem as mesmas roupas" (Stengel, 2011, p. 506). Indiferenciação que, muitas vezes, é propagada pela mídia.

Um aspecto salientado por Szapiro e Resende (2010) é que a juventude parece ter deixado de ser encarada como uma etapa da vida, um momento de transição entre a infância e a idade adulta, para tornar-se um ideal de existência a ser perseguido tanto pelos jovens quanto pelos adultos. Destacam as autoras que, na atualidade, se observa o enaltecimento de um estilo de vida jovem, enquanto o envelhecimento assume uma conotação pejorativa, fato que ganhou força com o desenvolvimento do conhecimento científico acerca dos processos de envelhecimento e saúde. "Manter-se jovem é essencialmente não se fixar, não se alienar no já realizado que já é, de imediato, passado" (Szapiro \& Resende, 2010, p.47). Nesse contexto, a tradição e a valorização da experiência das gerações anteriores tornaram-se desprovidas de sentido.

Outro ponto destacado pelas autoras é o de que há, na atualidade, um imperativo pela conquista do amor dos filhos, o que leva muitos pais e mães a sacrificarem o seu papel primordial na educação dos mesmos. Frente à demanda de amor que se coloca, a tarefa de educar acaba assumindo uma relevância secundária, pois importa mais a esses responsáveis receber o amor de sua prole do que desempenhar sua função na transmissão geracional. Para esses pais e mães, seria fundamental conseguir compreender que ocasionalmente precisarão dizer não, ainda que, como resposta, precisem lidar com o ressentimento de seus filhos (Szapiro \& Resende, 2010).

Costa (2006) menciona a responsabilidade dos familiares no acolhimento das novas gerações, destacando que, quando os responsáveis não tomam para si o papel da autoridade, abre-se uma lacuna que não poderá ser ocupada por nada, nem por ninguém.

Temos de convencer-nos de que a família, malgrado todas as limitações, ainda é a instituição cultural responsável pelo acolhimento das novas gerações, e que a sua pedra de toque é a confiança na autoridade. Se pais e adultos renunciam ao respeito que devem ter por sua função cultural, nada nem ninguém poderá ocupar este lugar (Costa, 2006, p.27).

Nova Perspectiva Sistêmica, v. 29, n. 66, p. 74-86, abril 2020. 
Thery (1998) chama atenção para a importância do sistema simbólico do parentesco, ressaltando que a família não pode ser vista, ou pensada, como um grupo social como outro qualquer. Neste sentido, Hurstel (2006) enfatiza que o lugar genealógico da criança não é idêntico ao do adulto. $\mathrm{Na}$ discussão sobre direitos e liberdades individuais, os direitos individuais não devem ser vistos como absolutos, independentes dos de interesse geral e daqueles da comunidade familiar - orientação que, no entendimento de Meulders-Klein (1993), muitos perseguem - pois, para a citada autora, dessa forma se caminharia para uma oposição entre o indivíduo e a família. Por esse ponto de vista, compreende que este é o sério desafio que hoje se apresenta, ou seja, como chegar a um equilíbrio entre os direitos e liberdades individuais e os de interesse geral e familiar, interrogação que também é feita por Commaille (2002).

\section{CONSIDERAÇÕES FINAIS}

A partir das inúmeras queixas de pais e mães que se dirigiam ao Conselho Tutelar relatando a perda da autoridade sobre seus filhos adolescentes e a dificuldade que sentiam para educá-los, buscou-se apontar e refletir sobre questões que possam estar contribuindo para o cenário apresentado.

Por meio da análise bibliográfica foi possível perceber que diversos autores (Costa, 2006; Dufour, 2009; Hurstel, 2006; Thery, 1998; Zanetti \& Gomes, 2011) compreendem que, na atualidade, vivencia-se certa fragilização da autoridade parental, fazendo questão de ressaltar a diferença conceitual entre autoridade parental e autoritarismo. Acreditam, contudo, que tais dificuldades extrapolam justificativas individuais que culpabilizam exclusivamente os responsáveis por questões que, aparentemente, encontram raízes em solo mais profundo. Nesse sentido, na busca de questões contemporâneas que podem estar colaborando para o quadro exposto, optou-se por circunscrever e analisar constantes e repetitivas queixas proferidas por pais e mães que procuram o Conselho Tutelar. Observou-se que, nos dias de hoje, certa (in)compreensão das leis de proteção à infância e à juventude, aliadas a um contexto de judicialização da vida, a medicalização da existência e a diluição das fronteiras geracionais são situações que, enlaçadas e difundidas pela mídia, podem contribuir para a fragilização da autoridade parental. Observa-se assim que, se no ano de 2006 Hurstel previa que faltava pouco para pais e mães se demitirem por não conseguirem manter sua autoridade sobre os filhos, nos dias de hoje parece que a previsão se concretizou para alguns responsáveis.

Frente às dificuldades direcionadas ao Conselho Tutelar torna-se importante refletir também sobre o papel a ser desempenhado por este órgão. Embora se possa pensar na participação dos conselheiros tutelares de forma auxiliar, estes não devem tomar para si a responsabilidade inerente aos pais, assumindo competências que pertencem a aqueles. A atuação dos conselheiros deve buscar fortalecer o lugar da autoridade parental, reconhecendo a sua imprescindibilidade na formação das novas gerações. Faz-se importante que, durante os atendimentos, conselheiros tutelares e equipe técnica possam oferecer aos responsáveis o suporte necessário para que sustentem o lugar da diferença e consigam levar a cabo o seu papel na transmissão geracional, o que certamente não significa que o conselheiro deva acolher a demanda para que ele próprio exerça a autoridade parental junto ao adolescente. 


\section{REFERÊNCIAS}

Arendt, H. (2016). Entre o passado e o futuro. (M. Barbosa, trad.). São Paulo: Perspectiva. (Trabalho original publicado em 1954)

Asth, F. C. (2010). O Grupo de pais como dispositivo de análise. In M. L. Nascimento \& E. Scheinvar (Orgs.), Intervenção Socioanalítica em Conselhos Tutelares (pp. 59-80). Rio de Janeiro: Lamparina.

Bezerra, B.(2010). A psiquiatria e a gestão tecnológica do bem-estar. In J. Freire (Org.), Ser Feliz Hoje: reflexões sobre o imperativo da felicidade (pp. 117-134). Rio de Janeiro: Editora FGV.

Brito, L. M. \& Rocha, M. L. (2016). Discutindo a indisciplina, a violência e o bullying na instituição escolar. Estudos e Pesquisas em Psicologia, Rio de Janeiro, 16(2), 332-345. Recuperado de http://www.e-publicacoes.uerj.br/ index.php/revispsi/article/view/29163/20634

Bruel, A. (1998). Um avenir pour la paternité? Paris: Syros.

Brzozowski, F. S. \& Caponi, S. N. (2013). Medicalização dos desvios de comportamento na infância: aspectos positivos e negativos. Psicologia: Ciência e Profissão Brasília, 33(1), 208-221. doi: 10.1590/S1414-98932013000100016.

Commaille, J. (2002). Famille: entre émancipation et protection sociale. In J. F. Dortier (Org.), Familles: permanence et métamorphose (pp. 243-252). Paris: Sciences Humaines.

Conselho Federal de Psicologia. (2012). Subsídios para a campanha Não à medicalização da vida: medicalização da educação. Recuperado de https://site. cfp.org.br/wp-content/uploads/2012/07/Caderno_AF.pdf

Costa, J. F. (2006). Família e Dignidade. In V Congresso Brasileiro de Direito de Família, Anais, Familia e dignidade humana (pp. 15-28). São Paulo: IOB Thomson.

Decotelli, K. M., Bohre, L. C. T., \& Bicalho, P. P. G. (2013). A droga da obediência: medicalização, infância e biopoder - notas sobre clínica e política. Psicologia: Ciência e Profissão, Brasília, 33(2) 446- 459. doi: 10.1590/ S1414-98932013000200014.

Dekeuwer-Défossez, F. (1999). Rénover lê droit de la famille. Propositions pour um droit adapte aux réalités et aux aspirations de notre temps. Paris: La documentation française.

Digiácomo, M. J. (2016). Consulta: Conselho Tutelar - Equipe Interdisciplinar Equipe Técnica a serviço do Conselho Tutelar. Recuperado de http://www. crianca.mppr.mp.br/pagina-2010.html

Dufour, D. R (2005). A arte de reduzir cabeças(S.R. Felgueiras, trad.). Rio de Janeiro: Companhia de Freud. (Trabalho original publicado em 2003)

Hurstel, $F_{n}$ (2006). Autoridade e transmissão da "dívida de vida": uma função fundamental dos pais. Epistemo-somática, Belo Horizonte, 3(2),163-173. Recuperado de http:// pepsic.bvsalud.org/pdf/epistemo/v3n2/v3n2a02.pdf

Instituto Brasileiro de Geografia e Estatística - (IBGE, 2016). Acesso à internet e à televisão e posse de telefone móvel celular para uso pessoal - 2015. Recuperado de https:// agenciadenoticias.ibge.gov.br/media/com mediaibge/arquivos/617a4c9e499e4a828 fe781592e62c864.pdf

Lei federal n. 8.069, de 13 de julho de 1990.(1990). Dispõe sobre o Estatuto da Criança e do Adolescente e dá outras providências. Brasília, DF: Governo Federal.

Legendre, P. (1999). Poder genealógico do Estado. In S. E. Altoé (Org.), Sujeito do Direito, Sujeito do Desejo. Direito e Psicanálise (pp. 85-94). Rio de Janeiro: Revinter. 
Meulders-Klein, M. T. (1993). Individualisme et communautarisme: 1'individual, famille et l'étaten Europe occidentale. Droit \& Societé, França, 23/24, 1-23.

Moreira, A. S. \& Coutinho, L. G. (2018). Efeitos da medicalização na travessia adolescente. Revista de Psicologia, Fortaleza, 9(1), 53-63. Recuperado de http://www.periodicos.ufc.br/psicologiaufc/article/view/20509

Nascimento, M. L. \& Scheinvar', E. (2010). Crises e deslocamentos como potência. In Intervenção Socioanalítica em Conselhos Tutelares (pp.19-36). Rio de Janeiro: Lamparina.

Oliveira. C. F \& Brito, L. M. (2013). Judicialização da vida na contemporaneidade. Psicologia: Ciência e Profissão, Brasília, 33(n. spe.), 78-89. Recuperado de http://www.scielo.br/pdf/pcp/v33nspe/v33speca09.pdf

Sarlo, B. (1994). Escenas de la vida posmoderna. Buenos Aires: Compañia Editora Espasa Calpe.

Stengel, M. (2011). O exercício da autoridade em famílias com filhos adolescentes. Psicologia em Revista, Belo Horizonte,17(3),502-521. Recuperado de http://pepsic.bvsalud.org/pdf/per/v17n3/v17n3a11.pdf

Sousa, A. M. (2014). A consagração das vítimas nas sociedades de segurança. Epos, Rio de Janeiro, 5(1), 29-56. Recuperado de http://pepsic.bvsalud.org/scielo. php? script $=$ sci abstract $\&$ pid $=$ S2178-700X2014000100003\&lng $=\mathrm{n}$

Szapiro, A. M. \& Resende, C. M. (2010). Juventude: etapa da vida ou estilo de vida? Psicologia \& Sociedade, Florianópolis, 22(1), 43-49. doi: 10.1590/ S0102-71822010000100006

Théry, I. (1998). Couple, Filiation et Parenté aujourd'hui Le droit face aux mutations de la famille et de la vie privée. Paris: Odile Jacob, Documentation française.

Zanetti, S. A \& Gomes, A. C (2009). A ausência do princípio de autoridade na família contemporânea brasileira. Psico, Porto Alegre, 40(2), 194-201. Recuperado de http://revistaseletronicas.pucrs.br/ojs/index.php/revistapsico/article/view/3726/4532

Zanetti, S. A, \& Gomes, A. C (2011). A "fragilização das funções parentais" na família contemporânea: determinantes e consequências. Temas em Psicologia, Ribeirão Preto, 19(2), 491-502. Recuperado de http://pepsic.bvsalud.org/pdf/ tp/v19n2/v19n2a12.pdf

\section{ÉRICA DOS SANTOS VIEIRA}

Psicóloga da Prefeitura Municipal de Niterói lotada em Conselho Tutelar. Professora nos cursos de graduação e pós-graduação da Universidade Estácio de Sá.

https://orcid.org/0000-0002-8424-9879

E-mail: psivieira@hotmail.com

\section{LEILA MARIA TORRACA DE BRITO}

Professora Titular do Departamento de Psicologia Social e Institucional da Universidade do Estado do Rio de Janeiro - UERJ.

https://orcid.org/0000-0001-9661-504X

E-mail: leila.torraca.brito@gmail.com 